\title{
ОСОБЕННОСТИ ПОЛИМОРФИЗМА ГЕНОВ ПРОВОСПАЛИТЕЛЬНЫХ ЦИТОКИНОВ У ДЕВОЧЕК, ПРЕДРАСПОЛОЖЕННЫХ К ЧАСТЫМ РЕСПИРАТОРНЫМ ЗАБОЛЕВАНИЯМ
}

А. В. Казакова ${ }^{1}$, Е. В. Уварова², Л. В. Лимарева ${ }^{1} \bowtie$, О. И. Линева ${ }^{1}$, Г. Н. Светлова ${ }^{1}$, А. А. Трупакова

${ }^{1}$ Самарский государственный медицинский университет, Самара, Россия

${ }^{2}$ Национальный медицинский исследовательский центр акушерства, гинекологии и перинатологии имени академика В. И. Кулакова, Москва, Россия

Респираторные заболевания (ОРЗ) относят к числу наиболее распространенных заболеваний детского возраста и служат поводом частого обращения за медицинской помощью. Повышенная заболеваемость детей определяется целым рядом факторов, в том числе наличием дисбаланса в системе цитокинов, уровень синтеза которых генетически детерминирован. Целью работы было проанализировать особенности распределения шести клинически значимых полиморфных локусов в генах провоспалительных цитокинов у девочек с частыми респираторными заболеваниями. Среди девочек 7-17 лет, проходящих плановый профилактический осмотр, на основании анамнеза была выделена группа часто болеющих детей.

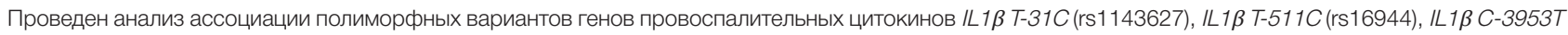

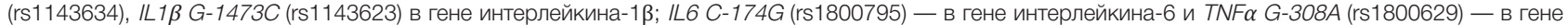
фактора некроза опухоли альфа с предрасположенностью к частым респираторным заболеваниям. Полиморфные варианты генов выявляли методом ПЦР с электрофоретической детекцией. Показано, что с повышенным риском рецидивирующих респираторных заболеваний у девочек 7-17 лет

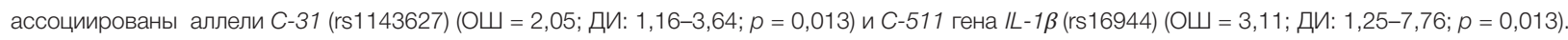

Ключевые слова: часто болеющие дети, провоспалительные цитокины, полиморфизм генов

Информация о вкладе авторов: А. В. Казакова - концепция и дизайн исследования, сбор и обработка материала, статобработка, написание и редактирование текста; Е. В. Уварова - концепция и дизайн исследования, редактирование текста; Л. В. Лимарева - концепция и дизайн исследования, статобработка, написание и редактирование текста; А. А. Трупакова - сбор и обработка материала; Г. Н. Светлова, О. И. Линева написание текста.

Соблюдение этических стандартов: исследование одобрено этическим комитетом СамГМУ (протокол № 5 от 20 апреля 2018 г.). Родителями участников исследования были подписаны добровольные информированные согласия на участие в исследовании и публикацию результатов.

$\bowtie$ Для корреспонденции: Лариса Владимировна Лимарева

ул. Гагарина, д. 20, г. Самара, 443079; larisa-limareva@yandex.ru

Статья получена: 02.12.2019 Статья принята к печати: 18.12.2019 Опубликована онлайн: 25.12.2019

DOI: $10.24075 /$ vrgmu.2019.087

\section{POLYMORPHISM OF PROINFLAMMATORY CYTOKINE GENES IN GIRLS PREDISPOSED TO RECURRENT RESPIRATORY INFECTIONS}

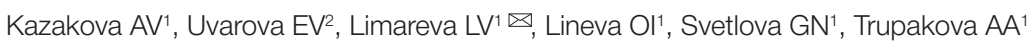

${ }_{1}$ Samara State Medical University, Samara

${ }^{2}$ Kulakov National Medical Research Center for Obstetrics, Gynecology, and Perinatology, Moscow

Acute respiratory infections (ARI) are very common in children and often prompt parents to seek medical advice. Increased susceptibility to ARI is caused by a number of factors, including genetically determined imbalances in cytokine production. The aim of this study was to analyze the frequency of 6 clinically relevant polymorphisms of proinflammatory cytokine genes in girls predisposed to recurrent respiratory infections. The study was conducted in girls aged 7-17 years who were undergoing a routine medical checkup. A group of children with frequent respiratory infections was identified. The following polymorphisms were analyzed for possible associations with predisposition to frequent respiratory infections: $I L 1 \beta T$-31C (rs 1143627 ), $I L 1 \beta T$ - $511 C$

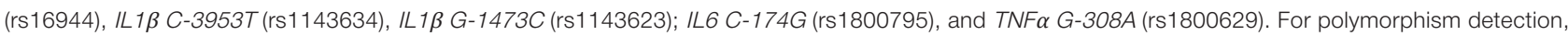
PCR and gel electrophoresis were used. The following alleles were found to be associated with an increased risk for recurrent respiratory infections in girls aged 7-17 years: $C-31$ ( $r$ 1143627) $(\mathrm{OR}=2.05$; $\mathrm{Cl}: 1.16-3.64 ; p=0.013)$ and $C$-511 (rs16944) (OR $=3.11 ; \mathrm{Cl}: 1.25-7.76 ; p=0.013)$ of the $/ L-1 \beta$ gene.

Keywords: recurrent respiratory infections in children, pro-inflammatory cytokines, gene polymorphism

Author contribution: Kazakova AV — conception and design of the study; data acquisition and statistical analysis; Uvarova EV — conception and design of the study; manuscript preparation; Limareva LV — conception and design of the study; statistical analysis; manuscript preparation; Trupakova AA — data acquisition; Svetlova GN, Lineva OI — manuscript preparation.

Compliance with ethical standards: the study was approved by the Ethics Committee of Samara State Medical University (Protocol № 5 dated April 20, 2018) Informed consent was obtained from the parents.

$\triangle$ Correspondence should be addressed: Larisa V. Limareva Gagarina, 20, Samara, 443079; larisa-limareva@yandex.ru

Received: 02.12.2019 Accepted: 18.12.2019 Published online: 25.12.2019

DOI: $10.24075 / \mathrm{brsmu} .2019 .087$

В настоящее время убедительно доказана ведущая роль иммунитета в развитии и течении заболеваний. Важнейшими медиаторами межклеточных взаимоотношений в иммунной системе являются цитокины, регулирующие иммуногенез в норме и при патологии [1, 2]. Дисбаланс про- и противовоспалительных цитокинов приводит к нарушению противоинфекционной защиты, а также к хронизации патологического процесса [3]. Активность синтеза цитокинов определяется экспрессией соответствующих генов, которая обусловлена не только влиянием персистирующих микроорганизмов, но и генетическими особенностями организма хозяина [4]. Существование однонуклеотидных замен (SNP) в генах человека, кодирующих иммунокомпетентные молекулы, определяет различные уровни их синтеза в ответ на инфекцию, что влияет на развитие и клиническое течение заболевания [5-7]. 
Верифицирован ряд полиморфных локусов промоторных регионов генов, связанных с продукцией провоспалительных цитокинов - IL1 $\beta$, IL6, TNF $\alpha$ и др. [8-12].

Острые респираторные заболевания (ОРЗ) относят к числу наиболее распространенных заболеваний детского возраста. В настоящее время к часто болеющим (более шести эпизодов в год) относят детей с повторной или рецидивирующей респираторной вирусной, бактериальной или смешанной инфекционной патологией ЛОР-органов (аденоидит, тонзиллит, отит), верхних (ларингит) или нижних (трахеит, бронхит, пневмония) дыхательных путей, развивающейся на фоне сниженного иммунитета или неадекватного лечения острого респираторного заболевания [13-15]. Повышенная заболеваемость детей обусловлена целым рядом факторов, в том числе генетическими. В настоящее время идет поиск возможных иммуногенетических маркеров этой предрасположенности.

Целью исследования было выявить ассоциации полиморфизма генов ключевых провоспалительных цитокинов с предрасположенностью К частым респираторным заболеваниям у девочек-школьниц в возрасте от 7 до 17 лет.

\section{ПАЦИЕНТЫ И МЕТОДЫ}

Всего были обследованы 116 девочек-школьниц в возрасте 7-17 лет, проживающих в городе Самаре, обратившихся к детскому гинекологу в рамках медицинских (профилактических) осмотров в течение 2014-2016 гг. Критерии включения в группу: возраст от 7 до 17 лет; отсутствие тяжелых органических патологий; соответствие физического, полового и психического развития возрастным нормативам. Критерии исключения: иной возраст; наличие тяжелых органических патологий; несоответствие развития возрастным нормативам. Были изучены особенности анамнеза (частота и характер течения острых респираторных заболеваний) и особенности распределения частот аллелей и генотипов полиморфных вариантов генов провоспалительных цитокинов методом ПЦР с электрофоретической детекцией результата с помощью тест-систем SNP-ЭКСПРЕCС («ЛИТЕХ»; Россия). Выявляли следующие точечные мутации генов:

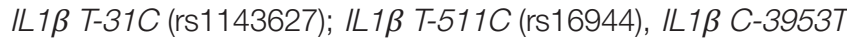
(rs1143634), IL1ß G-1473C (rs1143623) в гене интерлейкина1ß; IL6 C-174G (rs1800795) в гене интерлейкина-6, TNF $\alpha$ G-308A (rs1800629) в гене фактора некроза опухоли альфа. ДНК для исследования выделяли из буккального эпителия с помощью набора реагентов для экспрессвыделения ДНК из буккального соскоба того же производителя. Все исследуемые замены SNP связаны с характеристикой иммунного статуса человека и входят в список рекомендованных для изучения в клиникодиагностических целях на XXV-м Международном совещании по гистосовместимости и иммуногенетике, Бразилия, 2008 г. [16].

Для амплисикации использовали детектирующий термоциклер DTlite в комплектации 4S1 («ДНКТехнология»; Россия). Оценку соответствия выявленных частот генотипов закону Харди-Вайнберга в сравнении с ожидаемыми частотами генотипов равновесного распределения по критерию Пирсона $\chi^{2}$-квадрат, а также выявление ассоциаций и значимость различий в частоте встречаемости качественных признаков (расчет отношения шансов (ОШ) с указанием 95\%-го доверительного интервала (ДИ)) осуществляли online c помощью программы DeFinetti на сайте института генетики человека (Мюнхен, Германия) [17]. Анализировали данные, полученные при гипотезе доминирования минорной аллели, предполагающей оценку риска носительства данной аллели в любых сочетаниях.

\section{РЕЗУЛЬТАТЫ ИССЛЕДОВАНИЯ}

Анализ клинико-анамнестических данных показал, что у 56,9\% обследованных девочек острые респираторные заболевания возникали до 6-10 раз в год, что позволило отнести их к группе часто болеющих детей. У 10,6\% из них диагностирована хроническая патология ЛОР-органов (тонзиллит, фаринголарингит) с частыми обострениями (до 4-6 раз в год), которые проявлялись на фоне острой вирусной и/или бактериальной инфекции. В связи с этим все обследованные девочки были разделены на две группы: 65 девочек составили группу детей с частыми острыми респираторными заболеваниями (ОРЗ) и 51 девочка вошла в группу детей без частых ОРЗ.

Частота встречаемости генотипов полиморфных вариантов пяти из шести проанализированных полиморфизмов генов иммунной системы соответствовала равновесию Харди-Вайнберга, за исключением полиморфизма гена TNFQ (G-308A). В связи с этим указанный полиморфизм был исключен из дальнейшего анализа (см. табл.).

Анализ частот встречаемости аллелей и генотипов генов провоспалительных цитокинов в общей популяции девочек выявил преобладание носителей аллелей T-31, G-1473, C-3953 гена IL1 $\beta$ ( $<$ 0,05), определяющих высокие уровни синтеза соответствующего цитокина. В случае полиморфизма IL $1 \beta$ (T-511C) и IL6 (C-174G) имело место относительно равномерное распределение аллелей, ассоциированных с высоким и низким уровнями синтеза цитокина.

Сравнительная оценка отдельных полиморфизмов в клинически значимых локусах генов цитокинов, связанных с высокими и низкими уровнями их экспрессии, показала, что в группе часто болеющих девочек статистически значимо чаще встречаются аллели C в позициях 31 и 511 гена IL1 в в гомозиготном и гетерозиготном состояниях. Наличие аллеля C-31 повышало риск частых респираторных заболеваний в два раза (ОШ = 2,05; ДИ: 1,16-3,64) по сравнению с носительством аллеля T-31. Наибольший риск попадания в группу часто болеющих детей имеют девочки с генотипом СС по сравнению с гетерозиготами СТ (ОШ = 2,58; ДИ: 1,14-5,85), а также по сравнению с объединенной группой генотипов CT+ПТ (ОШ = 2,65; ДИ: 1,25-5,63). Наличие аллеля C-511 в любых вариантах также с высокой долей вероятности несло риски возникновения частых респираторных заболеваний (ОШ = 1,68; ДИ: 0,99-2,83; $p=0,053)$. Риск частых респираторных заболеваний статистически значимо повышался в три раза и более у носителей гомозиготы СС по сравнению с гетерозиготами CT (ОШ = 3,28; ДИ: 1,22-8,79), наличием гомозиготы ТТ (ОШ = 2,9; ДИ: 1,03-8,17) и по сравнению с объединенной группой генотипов СТ + ПТ (ОШ = 3,11; ДИ: $1,25-7,76)$ в локусе $-511 \mathrm{C} / \mathrm{T}$ гена $I L 1 \beta$.

Гипотеза наличия ассоциаций развития частых респираторных заболеваний с полиморфизмом в локусе гена IL6 (C-174G) не получила статистически значимых подтверждений, однако у часто болеющих девочек носительство аллеля $G$, связанного с высоким уровнем синтеза цитокина, встречалось в состоянии гомозиготы 
Таблица. Частота аллелей и генотипов полиморфных вариантов генов провоспалительных цитокинов у девочек 7-17 лет

\begin{tabular}{|c|c|c|c|c|c|}
\hline \multirow{2}{*}{$\begin{array}{l}\text { Ген, } \\
\text { полиморфизм }\end{array}$} & \multirow{2}{*}{$\begin{array}{l}\text { Аллель, } \\
\text { генотип }\end{array}$} & \multicolumn{4}{|c|}{ Частота встречаемости, абс./\% } \\
\hline & & $\begin{array}{l}\text { Все девочки } \\
n=116\end{array}$ & $\begin{array}{c}\text { Без частых ОР3 } \\
n=51\end{array}$ & $\begin{array}{l}\text { Часто болеющие } \\
\text { ОР3 } n=65\end{array}$ & $\begin{array}{l}\text { Отношение шансов (доверительный интервал) } \\
\text { при условии доминирования минорной аллели }\end{array}$ \\
\hline \multirow{5}{*}{ 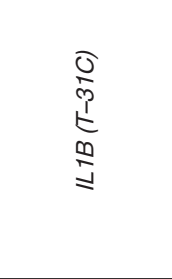 } & T & $100 / 67,0 \pm 3,3^{*}$ & $46 / 75,0 \pm 4,7$ & $54 / 60,0 \pm 4,4$ & \multirow{5}{*}{$\begin{array}{c}{[1]<->[2]^{\star *}: 2.05(1.16-3.64), \chi^{2}=6.18, p=0.013[11]<->[12]^{\star \star}} \\
2.58(1.14-5.85), \chi^{2}=5.28, p=0.022[11]<->[22]: \\
2.84(0,87-9,28), \chi^{2}=5.28, p=0.077[11]<->[12+22]^{\star *}: \\
2.65(1.25-5.63), \chi^{2}=6.53, p=0.011\end{array}$} \\
\hline & $\mathrm{C}$ & $61 / 33,0 \pm 3,3$ & $20 / 25,0 \pm 4,7$ & $41 / 40,0 \pm 4,4$ & \\
\hline & $\pi$ & $55 / 47,4$ & $31 / 60,8$ & $24 / 36,9$ & \\
\hline & CT & $45 / 38,8$ & $15 / 29,4$ & $30 / 46,2$ & \\
\hline & $\mathrm{CC}$ & $16 / 13,8$ & $5 / 9,8$ & $11 / 16,9$ & \\
\hline \multirow{5}{*}{ 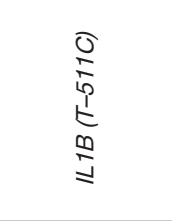 } & $\mathrm{T}$ & $78 / 45,0 \pm 3,4$ & $36 / 52 \pm 5,5$ & $42 / 39 \pm 4,1$ & \multirow{5}{*}{$\begin{array}{c}{[1]<->[2]: 1,68(0,99-2,83), \chi^{2}=3,74, p=0.053} \\
{[11]<->[12]^{\star *}: 3.28(1.22-8.79), \chi^{2}=5.80, p=0.016} \\
{[11]<->[22]^{\star *}: 2.90(1.03-8.17), \chi^{2}=3,13, p=0.042} \\
{[11]<->[12+22]^{\star *}: 3.11(1.25-7.76), \chi^{2}=6.24, p=0.013}\end{array}$} \\
\hline & C & $90 / 55,0 \pm 3,4$ & $34 / 48 \pm 5,5$ & $56 / 61 \pm 4,1$ & \\
\hline & $\pi$ & $26 / 22,4$ & $17 / 33,3$ & $9 / 13,8$ & \\
\hline & CT & $52 / 44,8$ & $19 / 37,3$ & $33 / 50,8$ & \\
\hline & $\mathrm{CC}$ & $38 / 32,8$ & $15 / 29,4$ & $23 / 35,4$ & \\
\hline \multirow{5}{*}{ 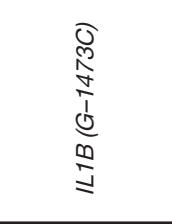 } & G & $94 / 57,0 \pm 3,3^{*}$ & $40 / 59,0 \pm 5,3$ & $54 / 55 \pm 4,1$ & \multirow{5}{*}{$\begin{array}{c}{[1]<->[2]: 1,15(0,68-1,94), \chi^{2}=0,28, p=0,600[11]<->[12]:} \\
2,00(0,86-4,63), \chi^{2}=2,65, p=0,104[11]<->[22]: \\
\left.1,11(0,39-3,18), \chi^{2}=0,04, p=0.844[11]<->12+22\right]: \\
1,69(0,77-3,68), \chi^{2}=1,72, p=0.189\end{array}$} \\
\hline & C & $78 / 43,0 \pm 3,3$ & $31 / 41 \pm 5,3$ & $47 / 45 \pm 4,1$ & \\
\hline & GG & $38 / 32,7$ & $20 / 39,2$ & $18 / 27,7$ & \\
\hline & GC & $56 / 48,3$ & $20 / 39,2$ & $36 / 55,4$ & \\
\hline & $\mathrm{CC}$ & $22 / 19,0$ & $11 / 21,6$ & $11 / 16,9$ & \\
\hline \multirow{5}{*}{ 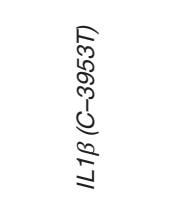 } & C & $109 / 78,0 \pm 2,8^{\star}$ & $48 / 80 \pm 4,2$ & $51 / 77,0 \pm 3,8$ & \multirow{5}{*}{$\begin{array}{c}{[1]<->[2]: 0,28(0,65-2,33), \chi^{2}=0,41, p=0,524[11]<->[12]:} \\
1,37(0,61-3,09), \chi^{2}=0,58, p=0.447[11]<->[22]: \\
1,16(0,24-5,57), \chi^{2}=0,04, p=0.851[11]<->[12+22]: \\
1,33(0,62-2,87), \chi^{2}=0,54, p=0.461\end{array}$} \\
\hline & $\mathrm{T}$ & $43 / 22,0 \pm 2,8$ & $17 / 20,0 \pm 4,2$ & $26 / 23,0 \pm 3,8$ & \\
\hline & $\mathrm{CC}$ & $73 / 62,9$ & $34 / 66,7$ & $39 / 60,0$ & \\
\hline & TC & $36 / 31,0$ & $14 / 27,5$ & $22 / 33,9$ & \\
\hline & $\pi$ & $7 / 6,0$ & $3 / 5,9$ & $4 / 6,2$ & \\
\hline \multirow{5}{*}{ 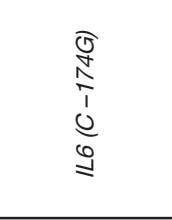 } & C & $79 / 45,0 \pm 3,4$ & $31 / 40,0 \pm 5,2$ & $48 / 48,0 \pm 4,3$ & \multirow{5}{*}{$\begin{array}{c}{[1]<->[2]: 0,72(0,42-1,21), \chi^{2}=1,58, p=0.209[11]<->[12]:} \\
1,05(0,40-2,76), \chi^{2}=0,01 p=0.925[11]<->[22]: \\
0,57(0,20-1,59), \chi^{2}=1,18, p=0.277[11]<->[12+22]: \\
0,81(0,33-2,00), \chi^{2}=0,20, p=0.652\end{array}$} \\
\hline & G & $91 / 55,0 \pm 3,4$ & $41 / 60,0 \pm 5,2$ & $50 / 52,0 \pm 4,3$ & \\
\hline & $\mathrm{CC}$ & $25 / 21,5$ & $10 / 19,6$ & $15 / 23,1$ & \\
\hline & CG & $54 / 46,5$ & $21 / 41,2$ & $33 / 50,8$ & \\
\hline & GG & $37 / 31,9$ & 20/39,2 & 17/26,2 & \\
\hline \multirow{5}{*}{ 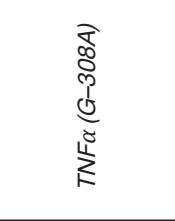 } & G & $32 / 18,0 \pm 2,9$ & \multirow{5}{*}{\multicolumn{3}{|c|}{$\begin{array}{l}\text { Не соответствует закону распределения Харди-Вайнберга } \\
\qquad(p=0,0001)\end{array}$}} \\
\hline & A & $106 / 92,0 \pm 2,9$ & & & \\
\hline & GG & $10 / 8,6$ & & & \\
\hline & GA & $22 / 19,0$ & & & \\
\hline & AA & $84 / 72,4$ & & & \\
\hline
\end{tabular}

Примечание: ОРЗ - острые респираторные заболевания; * - статистически значимые отличия частоты встречаемости аллели в локусе (р < 0,05); ** — статистически значимые ассоциации с повышенным риском рецидивирующих респираторных заболеваний.

в 1,5 раза реже, чем у девочек без частых простудных заболеваний (ОШ = 0,57; ДИ: 0,20-1,59; $p=0,277)$.

\section{ОБСУЖДЕНИЕ РЕЗУЛЬТАТОВ}

Частые и длительные респираторные заболевания, особенно в раннем возрасте - нерешенная медицинская проблема, создающая, в свою очередь, значительные социальные и экономические проблемы для детей, их семей и общества. Согласно современным представлениям, основной причиной высокой восприимчивости детей к инфекции является незрелость иммунной системы и наследственная предрасположенность к инфекционным заболеваниям $[18,19]$. Важную роль в противоинфекционной защите организма играют цитокины, регулирующие защитные реакции не только в рамках иммунной системы, но и на уровне всего организма. K настоящему времени накоплено большое количество данных о наличии функционального полиморфизма генов цитокинов, связанного с заменами единичных нуклеотидов (полиморфизм вследствие различия единичных нуклеотидов), которые приводят к количественным изменениям функционирования соответствующих генов. Такой функциональный полиморфизм генов цитокинов обусловливает индивидуальные наследственные колебания уровня их продукции, влияющие на развитие и исход инфекционных заболеваний и иммунопатологических процессов [20]. Провоспалительные цитокины играют центральную роль в формировании и регуляции воспалительных реакций, как во врожденном, так и в адаптивном иммунитете. В связи с этим изучение полиморфизма генов ключевых провоспалительных цитокинов может привести к новым направлениям в диагностике и лечении заболеваний [21, 22].

В нашем исследовании был проведен анализ ассоциаций полиморфизма генов ключевых провоспалительных цитокинов с предрасположенностью к частым респираторным заболеваниям у девочек-школьниц в возрасте от 7 до 17 лет. Оценивались клинически значимые 


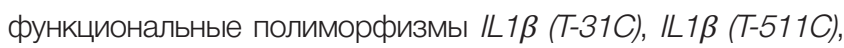

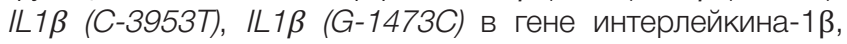
IL6 (C-174G) в гене интерлейкина-6, TNF $\alpha$ (G-308A) в гене фактора некроза опухоли альфа.

На первом этапе была проанализирована частота встречаемости аллелей и генотипов полиморфных вариантов генов провоспалительных цитокинов, а также проверено соответствие частот генотипов равновесию Харди-Вайнберга среди всех обследованных девочекшкольниц без учета предрасположенности к респираторным заболеваниям. Необходимость данного этапа объяснялась тем, что именно соответствие полученных в наблюдении частот генотипов равновесию Харди-Вайнберга позволяет судить об адекватности выбора субъектов для проведения генетических исследований. Исследование показало, что частота встречаемости генотипов пяти из шести проанализированных полиморфных вариантов соответствовала равновесию Харди-Вайнберга, за исключением полиморфизма TNF $\alpha$ (G-308A). Для полиморфизма G-308A гена $T N F \alpha$ наблюдаемая гетерозиготность в общей группе обследованных девочек отличалась от ожидаемой, что может быть связано как с недостаточным количеством числа наблюдений, так и с особенностями распределения аллелей данного локуса в исследуемой группе. В связи с этим указанный полиморфизм был исключен из дальнейшего анализа.

Анализ характера распределения аллелей и генотипов

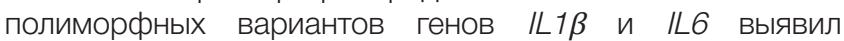
преобладание носителей аллелей T-31, G-1473, C-3953 гена IL $1 \beta$ и G-174 в гене IL6 в общей группе обследованных школьниц. Распределение аллелей полиморфизма $I L 1 \beta$ (T-511C) было относительно равномерным. Выявленный характер распределения аллелей и генотипов совпадал с описанным для европейской популяции женщин [23], а также русских женщин, проживающих в городе Москва [24], что, по-видимому, свидетельствует об эволюционном преимуществе аллелей, определяющих высокий уровень синтеза провоспалительных цитокинов, по крайней мере, в европеоидной популяции.

Последующий анализ ассоциаций между носительством аллелей/генов в полиморсных локусах провоспалительных цитокинов показал, что наличие аллелей C-31 и C-511 в гене IL1 $\beta$ статистически значимо повышало риск возникновения частых респираторных заболеваний в 2-3 раза, особенно при гомозиготном варианте. У часто болеющих девочек также в 1,5 раза реже встречался аллель $G$ в локусе 174 гена интерлейкина-6 ( $p$ > 0,05). Обнаруженная нами связь между полиморфными аллелями C-31, C-511 локусов гена IL1 $\beta$ и частыми респираторными заболеваниями согласуется с данными литературы, согласно которым данный интерлейкин играет центральную роль в генерации и регуляции противоинфекционного иммунитета, а носительство полиморфных вариантов в позициях $31 T$ и $511 T$ в большинстве случаев определяет увеличение выработки цитокина in vivo $\mathrm{n}$ in vitro по сравнению $\mathrm{c}$ аллелями С, носительство которых увеличивает частоту и тяжесть респираторных заболеваний у детей и взрослых [25-27].

Для ряда европеоидных популяций показано, что SNP IL1 $\beta$ (T-31C) находится в 100\%-м неравновесном сцеплении с SNP IL 1 $\beta$ (T-511C) [28], что, по-видимому, и объясняет выявление сходных рисков именно для данной пары полиморфизмов.

Вместе с тем тот факт, что нами была выявлена статистически значимая связь частых респираторных заболеваний только для двух полиморфизмов гена IL1 $\beta$, свидетельствует, на наш взгляд, о необходимости выделения среди часто болеющих детей подгрупп с преобладанием вирусных или бактериальных инфекций, наличием/отсутствием аллергических заболеваний и т. д., а также увеличения числа обследованных в группах. В то же время система цитокинов - это полиморфная регуляторная сеть медиаторов с высокой надежностью, плейотропным действием, биологические эффекты которой характеризуются каскадностью, разнообразием и нередко избыточностью [29]. Поэтому снижение экспрессии одного или нескольких генов цитокинов и уменьшение продукции соответствующих пептидных медиаторов не всегда будут сопровождаться наличием ярко выраженной патологии. Все это говорит о том, что при изучении влияния полиморфизма генов цитокинов на патологические состояния недостаточно анализа носительства отдельных полиморфных вариантов в нескольких генах цитокиновой сети. Необходимо учитывать сцепленное наследование, взаимное влияние, взаимодействие с рецепторами и другие факторы, влияющие на цитокиновый статус в норме и при развитии патологии.

\section{ВЫВОДЫ}

1. В исследованной группе девочек 7-17 лет, проживающих в г. Самаре, преобладают носители аллелей T-31, G-1473, C-3953 гена IL $1 \beta$ и G-174 в гене IL6. 2. Наличие аллелей C-31 и $C-511$ в гене IL1 $\beta$ ассоциировано с повышенным риском возникновения частых респираторных заболеваний. 3. В связи с выявлением связи между аллельными вариантами генов цитокинов и респираторными заболеваниями необходимо дальнейшее комплексное изучение функционального полиморфизма генов цитокинов для разработки новых направлений в диагностике, профилактике и персонификации лечения заболеваний. 4. При оценке индивидуальных иммуногенетических особенностей и поиске генетических маркеров для прогнозирования, профилактики и персонификации терапии недостаточно анализа носительства отдельных полиморфных вариантов в нескольких генах цитокиновой сети - необходимо учитывать сцепленное наследование, взаимное влияние, взаимодействие с рецепторами и другие факторы, влияющие на цитокиновый статус в норме и при развитии патологии.

\section{Литература}

1. Сепиашвили Р. И., Славянская Т. А. Стратегия и тактика комплексной иммунореабилитации больных с заболеваниями иммунной системы. Аллергология и иммунология. 2015; 16 (1): 51-7.

2. Кетлинский С. А., Симбирцев А. С. Цитокины. СПб.: Фолиант, 2008; 552 c.
3. Гуломов З. С., Симбирцев А. С., Янов Ю. К., Варюшина Е. А., Тырнова Е. В. Роль цитокинов при лечении острых и хронических заболеваний верхних дыхательных путей (Обзор литературы). Российская оториноларингология. 2008; 37 (6): 200-05. 
4. Прилепская В. Н., Летуновская А. Б., Донников А. Е. Микробиоценоз влагалища и полиморфизм генов цитокинов как маркер здоровья женщины (обзор литературы). Гинекология. 2015; 17 (2): 4-13.

5. Бодиенкова Г. М., Титова Ж. В. Роль полиморфизма и экспрессии отдельных генов цитокинов в формировании патологии (Обзор). Успехи современного естествознания. 2015; (1): 616-20

6. Нестерова И. В., Ковалева С. В., Клещенко Е. И., Шинкарева О. Н., Малиновская В. В., Выжлова Е. Н. Ретроспективный анализ клинической эффективности коротких курсов интерферонов в лечении ОРВИ у иммунокомпрометированных часто и длительно болеющих детей. Педиатрия. Журнал имени Г. Н. Сперанского. 2014; 93 (2): 62-7. DOI:10.24110/0031-403X-2014-93-2-62-67

7. Шевченко А. В., Голованова О. В., Коненков В. И. Особенности полиморфизма промоторных регионов генов цитокинов IL1, IL4, IL5, IL6, IL10 и TNF- $\alpha$ у европеоидного населения Западной Сибири. Иммунология. 2010; (4): 176-81.

8. Абрамов Д. Д., Кофиади И. А., Хаитов М. Р., Сергеев И. В., Трофимов Д. Ю., Гудима Г. О. и др. Особенности полиморфизма генов, регулирующих различные компоненты иммунного ответа, в русской популяции. Российский аллергологический журнал. 2012; (6): 72-5.

9. Прокофьев В. Ф., Шевченко А. В., Голованова О. В., Зонова Е. В., Королев М. А., Леонова Ю. Б. Комплексный анализ полиморфизма в промоторных участках генов цитокинов IL-1B T-31C, IL-6 G-174C, TNFA G-238A, TNFA G-308A, TNFA C-863A, IL-4 C-590T и IL-10 C-592 $\alpha$ в прогнозе эффекта от лечения ревматоидного артрита. Медицинская иммунология. 2010; (4): 361-74

10. Смольникова М. В., Смирнова С. В., Тютина О. С. Полиморфизм генов цитокинов при атопической бронхиальной астме. Сибирское медицинское обозрение. 2013; (2) 63-9.

11. Kutikhin AG, Brusina EB, Volkov AN, Yuzhalin AE, Zhivotovskiy AS. Correlation between genetic polymorphisms within IL-1B and TLR4 genes and cancer risk in a Russian population: a casecontrol study. Tumor Biol. 2014; 35 (5): 4821-30.

12. Zhu Q, Sun J, Chen Y. Preterm birth and single nucleotide polymorphisms in cytokine genes. Transl Pediatr. 2014; 3 (2): 120-34. DOI: 10.3978/j.issn.2224-4336.2014.03.02.

13. Абрамова Н. А., Савенкова М. С. Роль социальных и экологических факторов в формировании группы часто болеющих детей в социально благополучных семьях г. Москвы. Детские инфекции. 2013; (4): 52-7.

14. Юлиш Е. И., Ярошенко С. Я. Часто болеющие дети и тактика педиатра. Здоровье ребенка. 2013; 49 (6): 70-6.

15. Хлынина Ю. О., Крамарь Л. В. Современные подходы к

\section{References}

1. Sepiashvili RI, Slavyanskaya TA. Strategiya i taktika kompleksnoy immunoreabilitatsii bol'nykh s zabolevaniyami immunnoy sistemy. Allergologiya i immunologiya. 2015; 16 (1): 51-7. Russian.

2. Ketlinskiy SA, Simbirtsev AS. TSitokiny. SPb.: Foliant, 2008; 552 s. Russian.

3. Gulomov ZS, Simbirtsev AS, Yanov YuK, Varyushina EA, Tyrnova EV. Rol' tsitokinov pri lechenii ostrykh i khronicheskikh zabolevaniy verkhnikh dykhatel'nykh putey (Obzor literatury). Rossiyskaya otorinolaringologiya. 2008; 37 (6): 200-5. Russian.

4. Prilepskaya VN, Letunovskaya AB, Donnikov AE. Mikrobiotsenoz vlagalishcha i polimorfizm genov tsitokinov kak marker zdorov'ya zhenshchiny (obzor literatury). Ginekologiya. 2015; 17 (2): 4-13.

5. Bodiyenkova GM, Titova ZhV. Rol' polimorfizma i ekspressii otdel'nykh genov tsitokinov $v$ formirovanii patologii (Obzor). Uspekhi sovremennogo estestvoznaniya. 2015; (1): 616-20. Russian.

6. Nesterova IV, Kovaleva SV, Kleshchenko EI, Shinkareva ON, Malinovskaya W, Vyzhlova EN. Retrospektivnyy analiz klinicheskoy effektivnosti korotkikh kursov interferonov $v$ lechenii ORVI u immunokomprometirovannykh chasto i dlitel'no boleyushchikh профилактике и лечению ОРЗ у часто болеющих детей Лекарственный вестник. 2015; 59 (4): 40-5.

16. Marsh SG, Albert ED, Bodmer WF, Bontrop RE, Dupont B, Erlich HA et al. An update to HLA nomenclature, 2010. 2010; 45 (5): 846-8.

17. Доступно по ссылке: http://ihg.gsf.de/cgi-bin/hw/hwa1.pl.

18. Левина А. С., Бабаченко И. В., Скрипченко Н. В., Имянитов Е. Н. Этиологическая структура заболеваний у часто болеющих детей в зависимости от возраста. Российский вестник перинатологии и педиатрии. 2017; 62 (2): 72-7.

19. Esposito S, Bianchini S, Bosis S, Tagliabue C, Coro I, Argentiero A et al. A randomized, placebo-controlled, double-blinded, singlecentre, phase IV trial to assess the efficacy and safety of OM-85 in children suffering from recurrent respiratory tract infections. Transl Med. 2019 Aug 23; 17 (1): 284. DOI: 10.1186/s12967019-2040-y. PMID: 31443716 Free PMC Article.

20. Симбирцев А. С., Тотолян А. А. Цитокины в лабораторной диагностике. Инфекционные болезни: новости, мнения, обучение. 2015; (2): 82-98.

21. Казакова А. В., Уварова Е. В., Лимарева Л. В., Трупакова А. А Мишина А. И. Способ прогнозирования бактериального вульвовагинита у девочек в зависимости от стадии полового развития согласно шкале Таннера. Вестник РГМУ. 2019; (5): 116-22. DOI: 10.24075/vrgmu.2019.070.

22. Khazim K, Azulay EE, Kristal B, Cohen I. Interleukin 1 gene polymorphism and susceptibility to disease. Immunol Rev. 2018 Jan; 281 (1): 40-56. DOl: 10.1111/imr.12620.

23. Доступно по ссылке: http://www.ensembl.org/index.html.

24. Кофиади И. А., Кадочникова В. В., Абрамов Д. Д., Гончарова Е. В., Донников А. Е., Трофимов Д. Ю. Частота встречаемости 100 клинически значимых однонуклеотидных полиморфизмов у здоровых представителей русской популяции. Физиология и патология иммунной системы. 2011; (2): 3-10.

25. Терскова Н. В., Шнайдер Н. А., Вахрушев С. Г., Иконникова Е. В., Пилюгина М. С. Роль полиморфизма гена интерлейкина$1 \beta$ в развитии воспаления глоточной миндалины. Рос. оториноларингология. 2010; (6): 87-93.

26. Chen H, Wilkins LM, Aziz N. Single nucleotide polymorphisms in the human interleukin-1B gene affect transcription according to haplotype context. Hum Mol. Genet. 2006; (15): 519-29.

27. Todorović MM, Zvrko EZ. Immunoregulatory cytokines and chronic tonsillitis. Bosn J Basic Med Sci. 2013; 13 (4): 230-6. PMID: 24289758.

28. Громова А. Ю., Симбирцева А. С. Полиморфизм генов семейства IL1 человека. Цитокины и воспаление. 2005; (2): 3-12.

29. Цыган В. Н, Иванов А. М., Камилова Т. А., Протасов О. В. Артюшкин С. А. Генетический полиморфизм цитокинов. Вестник Российской военно-медицинской академии. 2010; 30 (2): 211-9.

detey. Pediatriya. ZHurnal imeni G.N. Speranskogo. 2014; 93 (2): 62-7. DOl:10.24110/0031-403X-2014-93-2-62-67. Russian.

7. Shevchenko AV, Golovanova OV, Konenkov VI. Osobennosti polimorfizma promotornykh regionov genov tsitokinov IL1, IL4, IL5, IL6, IL10 i TNF- $\alpha$ u evropeoidnogo naseleniya Zapadnoy Sibiri. Immunologiya. 2010; (4): 176-81. Russian.

8. Abramov DD, Kofiadi IA, Khaitov MR, Sergeyev IV, Trofimov DYu, Gudima GO, i dr. Osobennosti polimorfizma genov, reguliruyushchikh razlichnyye komponenty immunnogo otveta, russkoy populyatsii. Rossiyskiy allergologicheskiy zhurnal. 2012; (6): 72-5. Russian

9. Prokofyev VF, Shevchenko AV, Golovanova OV, Zonova EV, Korolev MA, Leonova YuB. Kompleksnyy analiz polimorfizma v promotornykh uchastkakh genov tsitokinov IL-1B T-31C, IL-6 G-174C, TNFA G-238A, TNFA G-308A, TNFA C-863A IL-4 C-590T i IL-10 C-592 $\alpha$ v prognoze effekta ot lecheniya revmatoidnogo artrita. Meditsinskaya immunologiya. 2010; (4) 361-74. Russian.

10. Smolnikova MV, Smirnova SV, Tyutina OS. Polimorfizm genov tsitokinov pri atopicheskoy bronkhial'noy astme. Sibirskoye 
meditsinskoye obozreniye. 2013; (2): 63-69. Russian.

11. Kutikhin AG, Brusina EB, Volkov AN, Yuzhalin AE, Zhivotovskiy AS. Correlation between genetic polymorphisms within IL-1B and TLR4 genes and cancer risk in a Russian population: a casecontrol study. Tumor Biol. 2014; 35 (5): 4821-30.

12. Zhu Q, Sun J, Chen Y. Preterm birth and single nucleotide polymorphisms in cytokine genes. Transl Pediatr. 2014; 3 (2): 120-134. DOI: 10.3978/j.issn.2224-4336.2014.03.02.

13. Abramova NA, Savenkova MS. Rol' sotsial'nykh i ekologicheskikh faktorov $v$ formirovanii gruppy chasto boleyushchikh detey $v$ sotsial'no blagopoluchnykh sem'yakh g. Moskvy. Detskiye infektsii. 2013; (4): 52-7. Russian.

14. Yulish El, Yaroshenko SyA. Chasto boleyushchiye deti i taktika pediatra. Zdorov'ye rebenka. 2013; 49 (6): 70-6. Russian.

15. Khlynina YuO, Kramar LV. Sovremennyye podkhody k profilaktike i lecheniyu ORZ u chasto boleyushchikh detey. Lekarstvennyy vestnik. 2015; 59 (4): 40-5. Russian.

16. Marsh SG, Albert ED, Bodmer WF, Bontrop RE, Dupont B, Erlich HA, et al. An update to HLA nomenclature, 2010. 2010; 45 (5): 846-8.

17. Available from: http://ing.gsf.de/cgi-bin/hw/hwa1.pl.

18. Levina AS, Babachenko IV, Skripchenko NV, Imyanitov EN. Etiologicheskaya struktura zabolevaniy u chasto boleyushchikh detey $\mathrm{v}$ zavisimosti ot vozrasta. Rossiyskiy vestnik perinatologii i pediatrii. 2017; 62 (2): 72-7. Russian.

19. Esposito S, Bianchini S, Bosis S, Tagliabue C, Coro I, Argentiero A, Principi N. A randomized, placebo-controlled, double-blinded, single-centre, phase IV trial to assess the efficacy and safety of $\mathrm{OM}-85$ in children suffering from recurrent respiratory tract infections. J Transl Med. 2019 Aug 23; 17 (1): 284. DOI: 10.1186/ s12967-019-2040-y. PMID: 31443716 Free PMC Article.

20. Simbirtsev AS, Totolyan AA. Tsitokiny v laboratornoy diagnostike.
Infektsionnyye bolezni: novosti, mneniya, obucheniye. 2015; (2): 82-98. Russian.

21. Kazakova AV, Uvarova EV, Limareva LV, Trupakova AA, Mishina Al. Sposob prognozirovaniya bakterial'nogo vul'vovaginita u devochek $v$ zavisimosti ot stadii polovogo razvitiya soglasno shkale Tannera. Vestnik RGMU. 2019; (5): 116-22. DOI: 10.24075/vrgmu.2019.070. Russian.

22. Khazim K, Azulay EE, Kristal B, Cohen I. Interleukin 1 gene polymorphism and susceptibility to disease. Immunol Rev. 2018 Jan; 281 (1): 40-56. DOI: 10.1111/imr.12620.

23. Available from: http://www.ensembl.org/index.html.

24. Kofiadi IA, Kadochnikova VV, Abramov DD, Goncharova EV, Donnikov AE, Trofimov DYu, i dr. Chastota vstrechayemosti 100 klinicheski znachimykh odnonukleotidnykh polimorfizmov u zdorovykh predstaviteley russkoy populyatsii. Fiziologiya patologiya immunnoy sistemy. 2011; (2): 3-10. Russian.

25. Terskova NV, Shnayder NA, Vakhrushev SG, Ikonnikova EV, Pilyugina MS. Rol' polimorfizma gena interleykina- $1 \beta \vee$ razviti vospaleniya glotochnoy mindaliny. Ros. otorinolaringologiya. 2010; (6): 87-93. Russian.

26. Chen H, Wilkins LM, Aziz N. Single nucleotide polymorphisms in the human interleukin-1B gene affect transcription according to haplotype context. Hum Mol Genet. 2006; (15): 519-29.

27. Todorović MM, Zvrko EZ. Immunoregulatory cytokines and chronic tonsillitis. Bosn J Basic Med Sci. 2013; 13 (4): 230-6. PMID: 24289758.

28. Gromova AYu, Simbirtseva AS. Polimorfizm genov semeystva IL-1 cheloveka. Tsitokiny i vospaleniye. 2005; (2): 3-12. Russian.

29. Tsygan VN, Ivanov AM, Kamilova TA, Protasov OV, Artyushkin SA. Geneticheskiy polimorfizm tsitokinov. Vestnik Rossiyskoy voyenno-meditsinskoy akademii. 2010; 30 (2): 211-9. Russian. 